\title{
Standardized patient program: Student feedback
}

\author{
Shankar P R ${ }^{1}$, Dwivedi N R ${ }^{2}$, Nandy A $^{3}$, Dubey A K ${ }^{4}$ \\ ${ }^{1}$ Chair of the Curriculum Committee and Professor of Pharmacology, ${ }^{2}$ Professor of Introduction to Clinical Medicine and \\ Physical Diagnosis and Director of the Standardized Patient program, ${ }^{3}$ Professor of Microbiology and Director of the \\ MD6 program, ${ }^{4}$ Dean of Basic Sciences, Xavier University School of Medicine, Oranjestad, Aruba
}

Objective: Standardized patients (SPs) are widely used in medical and other health professions education. At the Xavier University School of Medicine, Aruba SPs have been used for teaching-learning and assessment of basic science medical students since January 2013. The opinion of SPs about their involvement in teaching-learning and assessment of students has been recently studied. The present study had the objective of studying student perception about various aspects of the program. Materials and Methods: The study was conducted towards end of March and beginning of April 2016. Student perception regarding the program was studied by noting their degree of agreement with a set of 25 statements. Free text comments were also obtained. Gender, nationality and semester of study of the respondents was noted. The total score was compared among different subgroups of respondents. Results: Ninety-eight of the 107 students (91.6\%) participated. The mean \pm SD total score was $92.33 \pm 13.68$ (maximum possible score being 125). The scores were significantly higher among first semester students compared to other semesters. Students agreed that interacting with SPs will prepare them for interacting with patients, for their licensing exams and improve their clinical skills. Students learn how to interact with persons from a different cultural background. Suggestions for further improvement were also obtained. Conclusions: The response rate was high and students' perception of the SP program was positive. Our experiences would be of special interest to educators in other medical schools with small and/or new SP programs. Similar feedback could be obtained from other Caribbean schools with SP programs.

Key words: Caribbean, Early clinical exposure, Medical students, Medical schools, Standardized patients

\section{INTRODUCTION}

Standardized patients (SPs) are widely used in the teachinglearning and assessment of medical and other health professional students. SPs are trained actors or individuals who play the role of a patient suffering from a particular disease or diseases and other conditions both during teaching-learning sessions of health professions students and during assessments. SPs are widely used in the United States (US) as they present a uniform and standardized challenge to each learner. At the Xavier University School of Medicine (XUSOM), Aruba SPs have been used for teaching-learning and assessment of clinical skills during the basic sciences since spring 2013. SPs views about their role in teaching-learning and assessment at the institution was studied in a recent article. ${ }^{1} \mathrm{XUSOM}$, a private medical school admits students from the United States, Canada and other countries to the undergraduate medical (MD) course. Students complete the first two years (basic sciences) at Aruba and then complete their clinical rotations in affiliated hospitals in the US and Canada. The school admits students three times a year in January, May and September and a semester of study is of 15 weeks duration. ${ }^{2}$

Changes in healthcare delivery and technologies have meant a reduction in the number of inpatient beds available for 
patients and for student learning and in the duration of hospitalization. ${ }^{3}$ Many procedures including surgeries have become less invasive and many are being done as office procedures with the patient going home on the same day. With the increased emphasis on cost of healthcare delivery, organizations and governments are focusing on reducing the number of inpatient beds as one of the means to reduce the cost of treatment, where possible. SPs provide a reliable learning method, can offer valuable feedback and be used to test the acquisition of clinical skills by students. ${ }^{4}$ SPs have been used to teach and assess learning of communication skills by students. ${ }^{5}$ They have also been used for other purposes among both medical and other health professions students. A recent article describes the use of SPs to evaluate medical students' evidence-based medicine (EBM) skills. ${ }^{6}$ A structured encounter with a SP who was overweight resulted in a significant short term decrease in negative stereotypes about obese persons and a longer term increase in empathy. ${ }^{7}$ SPs have been used to teach medical students how to break bad news. ${ }^{8}$ The encounter of each student with the SP was videotaped and students in small groups reviewed the tapes in the presence of a clinician.

The opinion of SPs about various aspects of the standardized patient program at the institution was largely positive. ${ }^{1}$ Opinion of basic science undergraduate medical (MD) students about the SP program at the institution has not been obtained previously. Hence the present study was conducted to obtain information about student perception regarding the strengths and weakness of the SP program. Suggestions for further improvement of the program were also obtained.

\section{MATERIALS AND METHODS}

The present study was conducted during the last week of March and the first week of April 2016 at the institution. The questionnaire was developed by the authors with reference to the literature and also taking into consideration important features of the standardized patient program at the institution. Information obtained during the previous focus group discussion conducted with SPs was also used during questionnaire development. The questionnaire was circulated among other faculty members of the institution involved in the SP program for their comments. The questionnaire was not, however, pretested. As XUSOM is a small institution most faculty members with a medical background are involved with different aspects of the SP program. Their suggestions and comments were incorporated into the final version of the questionnaire. Gender, nationality and semester of study of the respondents was recorded. Their degree of agreement with a set of twenty-five statements was noted using a Likert type scale. Certain statements were worded negatively and their scores were reversed while calculating the total score. The respondents were also asked to enumerate two strengths of the SP program at the institution and two areas which may need improvement. The comments were noted and common ones tabulated.

Respondents were informed about the aims and objectives of the study and invited to participate. It was emphasized that participation in the study was voluntary. Written informed consent was obtained from all participants. The total score was compared among different subgroups of respondents. A p value less than 0.05 was considered as statistically significant. Cronbach's alpha was calculated as a measure of internal consistency of the questionnaire. The study was approved by the institutional review board of the institution vide notification XUSOM/IRB/2016/01.

\section{RESULTS}

A total of 98 of the 107 undergraduate basic science medical students $(91.6 \%)$ participated in the study. Table 1 shows the demographic characteristics of the respondents. Certain respondents did not complete some of the demographic details. Table 2 shows the mean scores for different statements. As mentioned in the Methods section, some of the statements were negatively worded and their scores were reversed while calculating the total scores. The statements whose scores were reversed have been indicated by an $*$ in the table.

The mean \pm SD total score was $92.33 \pm 13.68$ (maximum possible score being 125). Table 3 shows the mean total scores among different subgroups of respondents. The mean scores among different subgroups of respondents was

\begin{tabular}{|c|c|c|}
\hline Characteristic & Number $(\mathrm{N}=98)$ & Percentage \\
\hline \multicolumn{3}{|l|}{ Gender } \\
\hline Male & 46 & 46.9 \\
\hline Female & 47 & 48.0 \\
\hline Not completed & 5 & 5.1 \\
\hline \multicolumn{3}{|l|}{ Nationality } \\
\hline American & 39 & 39.8 \\
\hline Canadian & 33 & 33.7 \\
\hline Others & 17 & 17.3 \\
\hline Not completed & 9 & 9.2 \\
\hline \multicolumn{3}{|l|}{ Semester } \\
\hline First & 23 & 23.5 \\
\hline Second & 25 & 25.5 \\
\hline Fourth & 32 & 32.6 \\
\hline Fifth & 11 & 11.2 \\
\hline Sixth & 7 & 7.1 \\
\hline Not completed & 0 & 0 \\
\hline
\end{tabular}




\section{Table 2: Mean scores of different individual statements}

\begin{tabular}{|c|c|}
\hline Statement & Mean score \\
\hline A standardized patient $(\mathrm{SP})$ is a trained actor who plays the role of a patient & 4.23 \\
\hline SPs have been used in medical education since the 1960 s & 3.57 \\
\hline Reduced hospital stays and inpatient admissions were an important reason behind initiating SP programs & 3.59 \\
\hline SP programs were first started at the State University of New York* & 2.58 \\
\hline I enjoy interacting with the SPs during the teaching-learning process at XUSOM & 3.97 \\
\hline I enjoy interacting with the SPS during the OSCE at XUSOM & 3.99 \\
\hline I often feel intimidated by the SPs* & 3.37 \\
\hline I feel uncomfortable interacting with a SP of the opposite gender* & 3.75 \\
\hline The SPs provide valuable feedback during the teaching-learning process & 3.30 \\
\hline SPs play an important role in providing early clinical exposure in the institution & 4.31 \\
\hline SPs make the examinations more objective and standardized & 3.73 \\
\hline The SPs in the institution are well trained & 3.76 \\
\hline SPs will be widely used in my future practice and licensing exams & 3.83 \\
\hline Interacting with the SPs repeatedly helps us in developing a good relationship with them & 3.89 \\
\hline I am comfortable performing physical examination on SPs & 4.19 \\
\hline SPs are very cooperative with regard to both history talking and physical examination & 3.79 \\
\hline I face no language and comprehension problems when communicating with SPs & 3.94 \\
\hline The SPs provide a standardized response to each student & 3.84 \\
\hline Dr Harold Barrows was the educator who first initiated a SP program & 3.34 \\
\hline I support the use of relevant makeup and other aids which would help SPs portray different conditions more realistically & 3.92 \\
\hline I learn about interacting with persons belonging to different cultures/ethnicities through my interaction with SPs & 3.68 \\
\hline $\begin{array}{l}\text { Interacting with the same set of SPs throughout the basic science program makes me more comfortable and less } \\
\text { stressed out during the examination }\end{array}$ & 3.65 \\
\hline I occasionally encounter problems while communicating with the SPs* & 3.19 \\
\hline I am confident SPs will serve as an effective preparation for my future clinical training & 3.19 \\
\hline Virtual SPs are likely to be more widely used in future & 3.68 \\
\hline
\end{tabular}

compared using appropriate statistical tests. Independent samples t-test was used for dichotomous variables and analysis of variance (ANOVA) for others. A p value less than 0.05 was considered as statistically significant. The scores were higher among students belonging to other nationalities and among female students but the difference was not significant. The scores were significantly different among students of different semesters. Post hoc comparison showed the scores of first semester students was significantly higher compared to the fourth, fifth and sixth semesters.

Table 4 details the common free-text comments of the respondents. Among comments not shown in the table were SPs may not provide a consistent answer during repeated questioning, Respondents were of the opinion that SPs help students learn about interacting with persons of different cultures, greater clarity regarding what is expected from students may be required, some SPs may need to be 'nicer' to students, and they also suggested use of makeup and other aids for SPs. The Cronbach's alpha value of the questionnaire was 0.875 suggesting a high degree of internal consistency.

\section{DISCUSSION}

Student feedback about the SP program was positive with the mean total score being about $74 \%$ of the maximum

\begin{tabular}{|c|c|c|}
\hline Subgroups & Mean score & $P$ value \\
\hline \multicolumn{3}{|l|}{ Gender } \\
\hline Male & 91.38 & 0.982 \\
\hline Female & 94.06 & \\
\hline \multicolumn{3}{|l|}{ Nationality } \\
\hline American & 93.20 & 0.181 \\
\hline Canadian & 96.22 & \\
\hline Others & 97.79 & \\
\hline \multicolumn{3}{|c|}{ Semester of study } \\
\hline First & 103.28 & $<0.001$ \\
\hline Second & 93.64 & \\
\hline Fourth & 85.32 & \\
\hline Fifth & 89.91 & \\
\hline Sixth & 88.29 & \\
\hline
\end{tabular}

possible score. The mean total scores were higher among female students and among students of other nationalities but the difference was not significant. The score was significantly higher among the first semester students. Suggestions for further improvement and student perception regarding the strength of the SP program were also obtained.

The scores of the respondents regarding certain statements exploring their knowledge about historical aspects of the SP program was low. Respondents strongly agreed with the statement about SPs providing early clinical exposure at the institution and this was also noted in the free text 


\begin{tabular}{|c|c|}
\hline Comment & $\begin{array}{l}\text { Number of } \\
\text { respondents }\end{array}$ \\
\hline \multicolumn{2}{|l|}{ Strengths/advantages of the session } \\
\hline Will help students in dealing with patients & 33 \\
\hline Simulation of clinical experience & 15 \\
\hline Improves communication skills & 15 \\
\hline $\begin{array}{l}\text { Helps in applying the knowledge we have } \\
\text { gained }\end{array}$ & 6 \\
\hline SPs are well trained & 6 \\
\hline $\begin{array}{l}\text { Provides us practice with different patients/ } \\
\text { scenarios }\end{array}$ & 5 \\
\hline Provides hands-on experience & 4 \\
\hline \multicolumn{2}{|l|}{ Suggestions for further improvement } \\
\hline Greater number and variety of respondents & 16 \\
\hline More time to practice with SPs & 15 \\
\hline $\begin{array}{l}\text { SPs may need more training to answer } \\
\text { questions quickly }\end{array}$ & 7 \\
\hline $\begin{array}{l}\text { SPs should be more knowledgeable about } \\
\text { their assigned cases }\end{array}$ & 5 \\
\hline Greater access to the OSCE lab & 4 \\
\hline Improve cooperativeness of SPs & 4 \\
\hline Greater use of non-human SPs and simulation & 3 \\
\hline Greater number of OSCE stations & 2 \\
\hline
\end{tabular}

comments. We were happy to note that students were comfortable performing physical examination on SPs and there were no problems on both sides. One of the problems is the limited number of SPs available for teaching-learning and assessment at the institution. Students encounter the same group of SPs both during learning sessions and during the assessments. The SPs however, may be presenting/simulating different clinical condition during the learning and assessment sessions. Due to the wide range of diseases in each organ system a 'new' disease could be presented by the SP during the exam. Training using SPs is supplemented by visits to local general practitioners and a hospital observership. During their clinical postings in the US and Canada both real patients and SPs are used for testing students. SPs are used for testing during the United States Medical Licensing Exam step 2 clinical skills exam. This was also noted previously when the perception of SPs regarding their contribution to teaching-learning in the institution was studied. ${ }^{1}$ In Japan, a national survey was undertaken to examine the willingness of SPs to participate in the teaching of physical examination skills to undergraduate medical students. ${ }^{9}$ Only about $25 \%$ were willing for physical examination of their back, chest and abdomen and the willingness varied according to age and gender. We did not notice any difference in willingness for physical examination among SPs in the institution. The number of SPs in the institution is low (seven) and the Japanese study involved a large number of SPs from all over the country. Our students and SPs of both genders did not feel uncomfortable interacting with each other and even while performing physical examination. The willingness and level of comfort may be influenced by social and cultural factors. Gender can also influence and modify patient-doctor relationships. A recent article had examined gender relations among adherents of the Islamic faith occurring in the medical context. ${ }^{10}$

SPs was first used in medical education by Dr Harold S Barrows in 1963 at the University of Southern California in the US. ${ }^{11}$ The term standardized patient was coined by Geoffrey Noman emphasizing the fact that the challenge provided by the SP to each student remains the same. Dr Barrows has described the importance and usefulness of the SP in medical education. ${ }^{12}$ SPs provide students with an opportunity to develop their history taking and physical examination skills and can serve as a transition to the real patient. In offshore Caribbean medical schools which have their affiliated hospitals in the US and Canada, SPs serve as an important means of providing early clinical exposure (ECE) to the students. This was strongly emphasized by the respondents in their comments. The challenge of providing ECE in the institution was briefly addressed in a previous article. ${ }^{13}$

Only a few of the SPs provide feedback to students at the end of the encounter. The others are being trained to do so. SPs play an important role in providing feedback to students both during teaching-learning and assessment in different medical schools. An encounter with a SP of 30 minutes duration was followed by SP and tutor feedback using a video recording of the encounter. ${ }^{14}$ An article published in the journal Academic Medicine compared SPs and faculty in teaching medical interviewing skills to students. ${ }^{15}$ The authors concluded that SPs were at least as effective as faculty in bringing about changes in the interviewing skills of first year students. SPs were used in an introduction to psychotherapy course among first year psychiatry residents. ${ }^{16}$ Written feedback was provided to the residents using the session ratings completed by the SPs.

External aids have been used to strengthen teachinglearning provided by SPs. Tattoos had been used to simulate a malignant melanoma in a SP during a dermatology conference in Canada. ${ }^{17}$ The authors concluded that tattoos may be used to simulate a variety of skin conditions and enhance the learning experience of medical students. SPs have been widely used in Anglo-American countries but were first introduced in Germany between 1998 and 2000. In Germany SPs are used to teach communication skills and also for assessment of student competence. ${ }^{18}$ At XUSOM, Aruba due to a number of reasons which have been described previously ${ }^{1}$ the number of SPs is low. SPs simulate a variety of diseases and students interact with the same SPs throughout the basic sciences. At the University of Louisville School of Medicine in the US 
a series of nine longitudinal SP cases was developed in which the same SP would portray the same patient with the same students across 19 encounters during the basic sciences. ${ }^{19}$ Students had more time to concentrate on the communication aspects of the SP encounter as they did not need to spend as much time learning about the patient and his/her medical history.

Virtual patients are being increasingly used in medical education. A virtual patient (VP) was used to teach empathetic communication to first year medical students. ${ }^{20}$ Contact with and feedback on empathy in a VP encounter increased students' empathy during subsequent encounters with a SP. VPs could provide students with a controllable, secure and safe learning environment along with the opportunity for extensive, repetitive practice with feedback according to the authors of a paper published in 2006. ${ }^{21}$ In the ensuing ten years there have been tremendous improvements in the technology. VPs have been also used to develop the clinical skills of healthcare professionals in a resource limited setting in Africa. ${ }^{22}$

At the institution the SP program has only recently been introduced (three years old) and seven SPs are involved in the program as described prevuiously. ${ }^{1}$ Most faculty members involved with the program also hold other responsibilities and are not exclusively devoted to the program. A room where objective structured clinical examinations can be conducted and the encounters can be video recorded and feedback provided to the students is available. ${ }^{13} \mathrm{SP}$ programs have been mentioned in the websites of some Caribbean medical schools but we could not come across published descriptions of these programs in the scientific literature. The small populations of many of theisland nations where these schools are located and the variety of languages spoken on the islands may be challenges in training SPs and in initiating and standardizing the program. Aruba, the island country where XUSOM is located has a population of over one hundred thousand inhabitants and though the native language of the country is Papiamento, many citizens and residents are fluent in multiple languages including English. Aruba is a multicultural country and though the social and cultural norms may be different from the US and Canada there are frequent interactions between citizens of these countries. Also the US and Canadian societies are becoming increasingly multicultural and learning to cater to the needs of a diverse population is an important competency for doctors. ${ }^{23,24}$ Certain institutions have been able to devote greater resources and offer specialized training modules to those involved in the SP program. ${ }^{25}$

The institution plans to expand the SP program and train more individuals from Aruba to be SPs. Specialized facilities for the program will be constructed at the new campus which is under development. At present SPs are trained principally by the second author with inputs provided by others. SPs act out their illness scripts in pairs and the SPs who have been in the program for a longer duration provide inputs to the newer SPs. In their free text comments a few respondents mentioned SPs may need to be more consistent in their answers which may be an issue to be addressed. They also mentioned about a greater number of SPs and greater variety of conditions to be portrayed by SPs. Recruiting greater number of SPs continues to be a challenge due to the small population of the island and language issues. Recruiting students studying in other institutions on the island to portray some conditions could be an option. An article published in 2009 examined SP practices in selected medical schools in the US and Canada. ${ }^{26}$ The programs were larger compared to the one in $\mathrm{xxx}$ and reported hiring between 51 to 75 SPs annually. Physical examination, references and background checks were not conducted before hiring SPs and the average number of hours before a SP performed a role was 5.5.

The response rate to the study was high and most respondents provided valuable free text comments. Some of the respondents did not complete all the required demographic characteristics. The questionnaire used was developed by the authors and though inputs were obtained from other faculty members the questionnaire was not pretested and validated. Response was only obtained using a questionnaire and though respondents could provide free text comments the information obtained from the questionnaire was not triangulated with information obtained from other sources.

\section{CONCLUSIONS}

Student response to the study was high and they were positive about the SP program at the institution. Their degree of agreements with certain statements was low. Respondents agreed that SPs provide opportunities for early clinical exposure, and will prepare them for their future clinical postings and licensing examinations. Suggestions for improvement were also obtained. SPs have been used in the institution now for over three years. Our experiences will be of interest to educators in other medical schools with small and recently initiated SP programs. As mentioned previously we have come across descriptions of SP programs in the websites of other Caribbean medical schools. Similar studies could be conducted in other Caribbean medical schools with SP programs. Like in the US and Canada a region wide study of SP programs in Caribbean medical schools could be considered in the future. 


\section{ACKNOWLEDGEMENTS}

The authors acknowledge all the standardized patients who have participated in the SP program. They acknowledge all faculty members who have been associated with the program. They thank all students who participated in the study.

\section{REFERENCES}

1. Shankar PR and Dwivedi NR. Standardized patient's views about their role in the teaching-learning process of undergraduate basic science medical students. J ClinDiagn Res 2016;10 (6):JC01-JC05.

2. Shankar PR, Balasubramanium R, Dwivedi NR and Nuguri V. Student feedback about the integrated curriculum in a Caribbean medical school. J EducEval Health Prof2014;11:23.

3. McGraw RC and O'Connor HM. Standardized patients in the early acquisition of clinical skills. Med Educ 1999;33:572-578.

4. Van der Vleuten CPM and Swanson DB. Assessment of clinical skills with standardized patients. State of the art. Teach Learn Med 1990;2:58-76.

5. Bosse HM, Nickel M, Huwendiek S, Schultz JH and Nikendei C. Cost-effectiveness of peer role play and standardized patients in undergraduate communication training. BMC Med Educ 2015;15:183.

6. Amini R, Hernandez NC, Keim SM and Gordon PR. Using standardized patients to evaluate medical students' evidence-based medicine skills. J Evid Based Med 2016;9:38-42.

7. Kushner RF, Zeiss DM, Feinglass JM and Yelen M. An obesity educational intervention for medical students addressing weight bias and communication skills using standardized patients. BMC Med Educ 2014;14:53.

8. Kiluk JV, Dessureault S and Quinn G. Teaching medical students how to break bad news with standardized patients. J Cancer Educ 2012;27:277-280.

9. Abe K, Suzuki T, Fujisaki K and Ban N. A national survey to explore the willingness of Japanese standardized patients to participate in teaching physical examination skills to undergraduate medical students. Teach Learn Med 2009;21:240-247.

10. Padela Al and delPozo PR. Muslim patients and cross-gender interactions in medicine: an Islamic bioethical perspective. J Med Ethics 2011;37:40-44.

11. Wallace P. Following the threads of an innovation: The history of standardized patients in medical education. Caduceus 1997; 13:5-28.

12. Barrows HS: An overview of the uses of standardized patients for teaching and evaluating clinical skills. Acad

\section{Med1993;68:443-451.}

13. Shankar PR and Dwivedi NR. Using standardized patients for teaching-learning and assessment in a Caribbean medical school.Education in Medicine Journal 2015;7:e78-e79.

14. Myung SJ, Kang SH, Kim YS, Lee EB, Shin JS, Shin HY, et al. The use of standardized patients to teach medical students clinical skills in ambulatory care settings. Med Teach 2010;32:e467-e470.

15. Vannatta JB, Smith KR, Crandall S, Fischer PC, and Williams, K. Comparison of standardized patients and faculty in teaching medical interviewing. Acad Med 1996;71:1360-1362.

16. Klamen DL and Yudkowsky R. Using standardized patients for formative feedback in an introduction to psychotherapy course. Acad Psychiatry 2002;26:168-172.

17. Langley RG, Tyler SA, Ornstein AE, Sutherland AE and Mosher LM. Temporary tattoos to simulate skin disease: Report and validation of a novel teaching tool. Acad Med 2009;84:950-953.

18. Fröhmel A, Burger $W$ and Ortwein $H$. [Integration of simulated patients into the study of human medicine in Germany]. Dtsch Med Wochenschr 2007;132:549-554.

19. Kodner C and Bohnert C. The Longitudinal Standardized Patient Project: innovation from necessity. Acad Med 2015;90:317-320.

20. Foster A, Chaudhary N, Kim T, Waller JL, Wong J, Borish M, et al. Using Virtual Patients to Teach Empathy: A Randomized Controlled Study to Enhance Medical Students' Empathic Communication. Simul Healthc 2016;11 (3):181-189.

21. Stevens A, Hernandez J, Johnsen K, Dickerson R, Raij A, Harrison $C$, et al. The use of virtual patients to teach medical students history taking and communication skills. Am J Surg 2006;191:806-811.

22. Bediang G, Franck C, Raetzo MA, Doell J, Ba M, Kamga Y, et al. Developing clinical skills using a virtual patient simulator in a resource-limited setting. Stud Health Technol Inform 2013;192:102-106.

23. Fortin S and Maynard S. Diversity, Conflict, and Recognition in Hospital Medical Practice. Cult Med Psychiatry 2015 Jul 1. [Epub ahead of print]

24. Chang ES, Simon $M$ and Dong $X$. Integrating cultural humility into health care professional education and training. Adv Health SciEduc Theory Pract 2012;17:269-278.

25. Al-Shawwa LA and Hagi SK. Design and work plan for establishing a standardized patient (SP) program at King Abdul-Aziz University: a "How to" guide. Med. J. Cairo Univ 2011;79:227-232.

26. Howley LD, Gliva-McConvey G, Thornton J and Association of Standardized Patient Educators (ASPE).Standardized patient practices: initial report on the survey of US and Canadian medical schools. Med Educ Online 2009;14:7.

\section{Authors Contribution:}

PRS - was involved in conceptualizing the study, designing the questionnaire, analyzing the data, reviewing the literature, writing the manuscript and revising it for intellectual content. NRD- helped in conceptualizing the study, conduct of the study, review of literature and writing the manuscript. AN - was involved in study conceptualization, collecting the data, analysis of data and helped in writing the manuscript. AKD - was involved in study conceptualization, helped in data acquisition, review of literature and in writing the manuscript. All authors have read and approved the final submitted version of the manuscript.

Source of Support: Nil, Conflict of Interest: None declared. 